\title{
ACTIVISATION OF THE CREATIVE POTENTIAL IN 7/8-YEAR OLD CHILDREN BY IMPLEMENTATION OF MIXED PAINTING TECHNIQUES IN FINE ART EDUCATION
}

\author{
Petar Petrov $^{1}$
}

\begin{abstract}
:
Introduction: The article explores some processes that activate the creative potential of 7/8- year old children after mixed painting techniques introduction and application. Problems on a theoretical and empirical level are discussed, based primarily on the children's creative activity results and determined by the degrees of free experimental application of painting and nonpainting materials.

Study Objective: The usage of some mixed techniques in the fine arts is considered and how they reflect on the dynamics of the children's education creative process.

Methods: During the experimental work, the following methods are applied: monitoring and analysing the processes of working with different materials, experimenting with mixed painting techniques, composition analysis, image and richness of the expression means.

Results: In the course of the study, it is established that the usage of more than one material for the pictorial activity significantly increases child creativity and better image in graphic and artistic terms are acquired, composition and richness of expression means are attained.

Conclusions: The application of mixed painting techniques in fine art education of 7/8-year olds increases the creative activity, builds a lasting interest in the fine art, and enhances the emotional and aesthetic impact.
\end{abstract}

UDC Classification: 7.02, DOI: 10.12955/cbup.v7.1420

Keywords: mixed painting techniques, creative activity, aesthetic impact

\section{Introduction}

One of the main tasks of modern education is to develop creative thinking in students. Modern life development requires the education of creative-thinking people with nonstandard ideas. The formation of creative thinking is impossible without creating problem situations in the learning process. Fine art classes provide many opportunities for this. Changing the stereotype of teaching, using non-traditional painting ways, encourages children towards creative thinking and the development of imagination.

\section{Study objective}

The study aims to track one of the ways to increase the creativity of 7/8-year olds. The learning process in primary school is characterized by a lot of dynamics and the accumulation of large amounts of information. This largely shifts the attention from the fine arts. At this age, children are familiar with the fine art materials and their capabilities but conducting lessons in the same model with standard materials usage leads to a lack of motivation and creativity. By painting at this age, according to Vygotsky, the problem is that the creative imagination activity is no longer enough. It is necessary that the child acquires special artistic habits and skills related to the possibilities of the materials (Vigotski, 1982). These skills are acquired through experimentation, material properties and various techniques.

Increasing the number of materials used in one painting, as well as a combination of pictorial with nonpictorial materials makes the art process more interesting, develops fantasy and the imagination. The variety of possible mixed painting techniques contributes to self-expression creativity. The implementation of various solutions Zlateva (2005) defines as a provocation for the child's thought, his/her fantasy and imagination. While applying only one option leads to mechanical copying (Zlateva, 2005)

The usage of non-standard materials and mixed painting techniques in fine art began with the modern art advent in the late 19th century. The used materials are no longer of artistic value, but they are subordinate to the artistic idea. According to Marinov (2002), it is assumed that the art not only reflects the objective reality, but in the social aspect it reflects the artist's attitude towards reality, his/her understanding of phenomena, objects and events. A visible, concrete form of experience is transmitted. The means of expression and ways of treatment pictorial materials combined with non-pictorial, merging art and reality are changed (Marinov, 2002). The involvement of modern and contemporary art expression means that creative activity in fine art education of 7/8-year-olds significantly increases.

\footnotetext{
${ }^{1}$ Trakia University, Faculty of Education, Stara Zagora, Bulgaria, art.petrof@abv.bg
} 
Moinova takes contemporary art as an incentive for creativity. The creative process is individual but it must be stimulated so everyone can feel their vocation (Moinova, 2016)

The study was conducted with 7/8-year-old children, during regular fine art classes in primary school. Two classes with one topic were conducted. Through a lecture, children were introduced into the subject and the main moments of imagery were characterized. In the first lesson, they chose the fine art materials they would work with. It was found that the paintings were executed in a linear manner, mainly with traditional pencils and penmasters. Most of them lacked coloring and completeness. In the second lesson, they were given the opportunity to include other materials in their paintings. The application of the techniques, over-painting, combining pictorial and non-pictorial materials were demonstrated. The creation of a problematic situation with the provision of mixed painting techniques provoked the creative imagination of the children. This affected the quality of the images, their coloring and completeness.

The results indicators were as follows:

Composition.

There are several composing constructions in the paintings of 7/8-year-old children. Although only few, but in some children the composition is unorganized, the elements are chaotic and unrelated. As a stereotype of pre-school age, the frieze composition is most widely used. The frieze construction of the elements is an easy way to accomplish the task without using fantasy and imagination. The more advanced children group the elements on a spatial principle. Also, the planar construction appears as a way of composing construction.

Image quality.

Image quality criteria are to achieve detail, construction, number of images, and non-standard images. The search for detail in the objects is typical at this age. $7 / 8$ year-olds have visual experience and more accurately depict individual elements. Their knowledge of the surrounding reality helps them construct and saturate the painting with many images properly. Non-standard constructive solutions are an expression of creativity.

The richness of expression means

During this period of the children's development, there is a pictorial activity stagnation as a result of the dynamics of the learning process and the writing mastery. Most of the children proceed standardly performing the tasks and use only one pictorial material. Typically, these are similar to the writing tools: pencils or penmasters. More than one material is used when the teacher requires it. The 7/8-year-olds aim for more complete paintings and fill with colours the entire image space; thus they achieve a stronger emotional impact. Table 1 presents the indicators and the different grades of evaluation.

\begin{tabular}{||c|c|c|c|c|}
\hline \multicolumn{2}{|c|}{ Table 1: Indicators and the different grades of evaluation } \\
\hline Indicators & Low level & Average level & Good level & High level \\
\hline Composition & $\begin{array}{c}\text { Unorganized } \\
\text { composition }\end{array}$ & $\begin{array}{c}\text { Frieze } \\
\text { composition }\end{array}$ & $\begin{array}{c}\text { Spatial } \\
\text { construction }\end{array}$ & $\begin{array}{c}\text { Planar } \\
\text { construction }\end{array}$ \\
\hline $\begin{array}{c}\text { Image quality } \\
\text { Intricacy }\end{array}$ & Construction & $\begin{array}{c}\text { Number of } \\
\text { images }\end{array}$ & $\begin{array}{c}\text { Non- } \\
\text { standardness }\end{array}$ \\
$\begin{array}{c}\text { Richness of } \\
\text { expression } \\
\text { means }\end{array}$ & $\begin{array}{c}\text { Using one } \\
\text { material }\end{array}$ & $\begin{array}{c}\text { Using more than } \\
\text { one material }\end{array}$ & $\begin{array}{c}\text { Completion } \\
\text { level(filling the } \\
\text { pictorial space) }\end{array}$ & $\begin{array}{c}\text { Emotional } \\
\text { impact }\end{array}$ \\
\hline Source: Author & \multicolumn{3}{|l}{} \\
\hline
\end{tabular}




\section{Results}

The results of the paintings appraisal from the first occupation - Figure 1, show that in standard fine art classes where students are using traditional materials and techniques, they work mechanically. The composite construction is at an average level and the frizz composition is used at a basic level. Children are used to this model of grouping the elements in the pictorial field and using it as an easy way to accomplish the assigned tasks. The paintings with spatial and planar construction are very few. The image quality is also average. Slightly higher construction indicators and the number of the images are observed. In the first occupation all children used only the known pencils and penmasters. Most paintings were executed linearly without filling of the pictorial space.

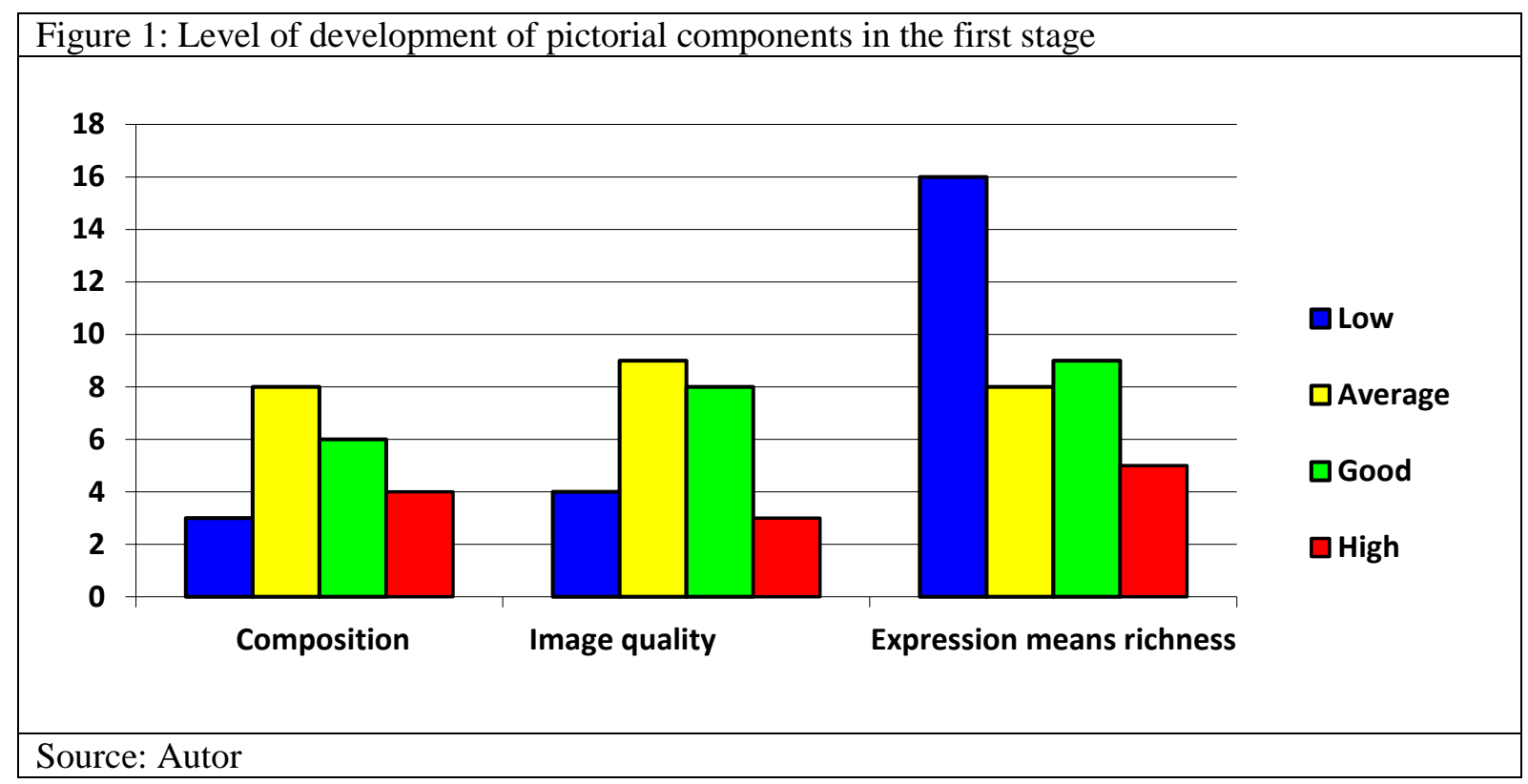

The second lesson results - Figure 2, established that with the usage of mixed painting techniques, evaluation levels increase. More children show greater results during the composition construction. The painting quality, the number of images increases and the non-standard solutions are improved. All children use more than one material, mixing pictorial and non-pictorial materials. The painting have a larger completion level and a greater emotional impact.

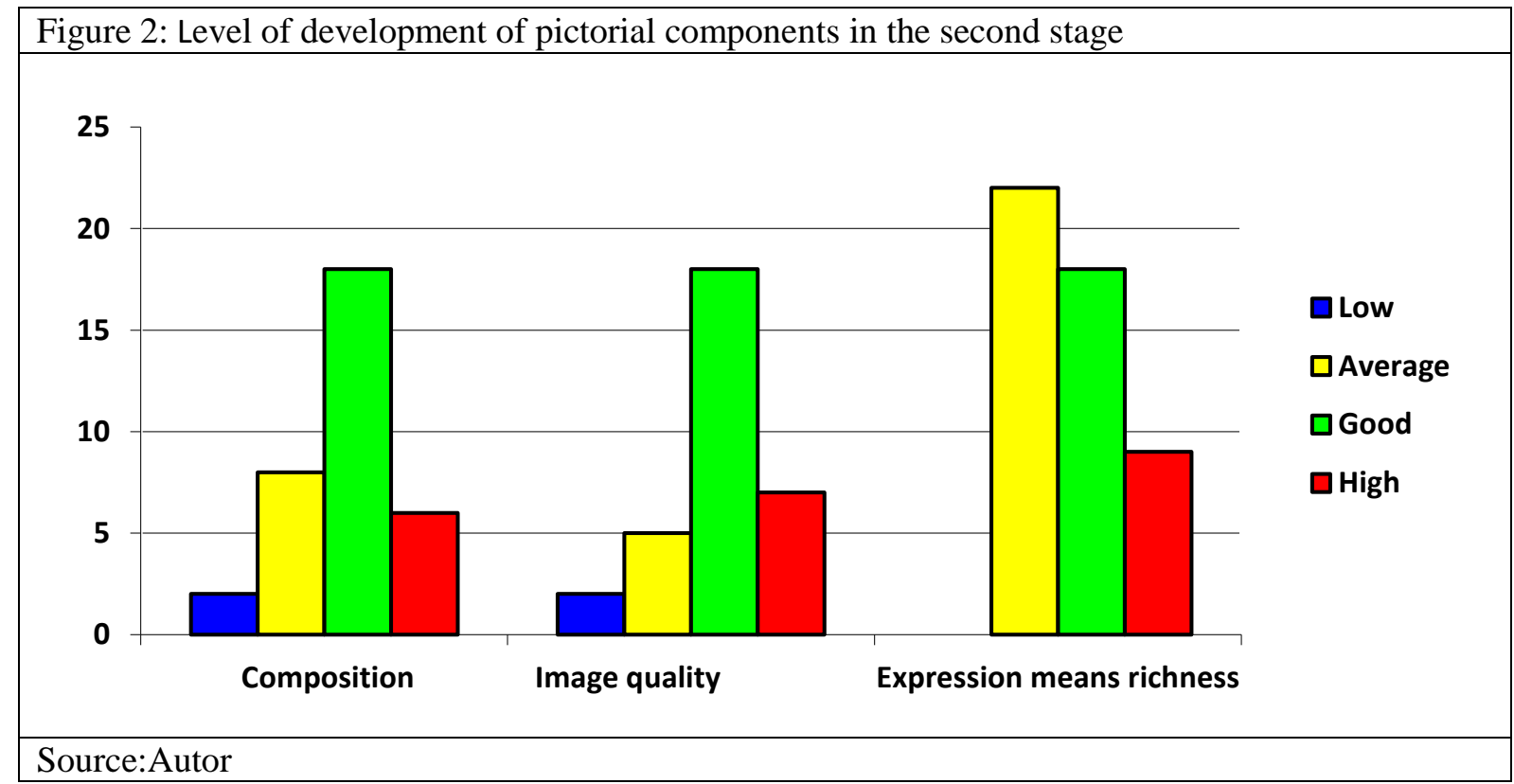

Both lessons presented illustrations with children's paintings that show the results achieved. The differences between the drawings from the first and the second lessons are clearly visible. By using 
mixed painting techniques, combining pictorial and non-pictorial materials, children work creatively with fantasy and imagination.

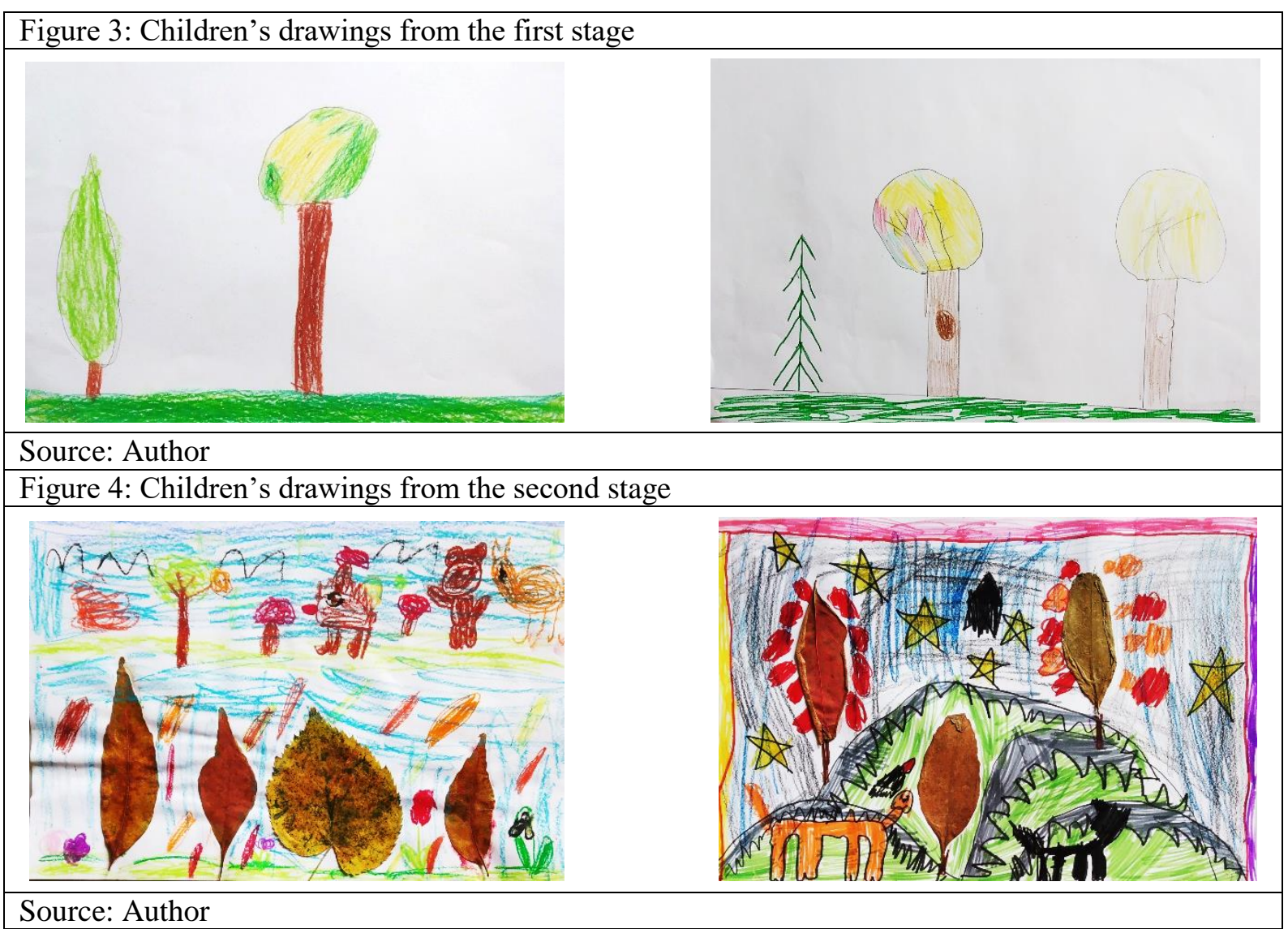

\section{Conclusion}

The study results show categorically that the usage of mixed painting techniques in the art education of $7 / 8$ year-olds significantly increase their creative activity. The inclusion of more pictorial and nonpictorial materials in the painting process improves image quality and compositional construction, enhancing the expression means. The usage of mixed painting techniques develops the imagination and fantasy of children and gives them the freedom for emotional expression. It helps to overcome their fear of the specificity of the image and allows for more free reality interpretation.

In conclusion we can say that the application of mixed painting techniques in the art education of 7/8year-old children stimulates their creative potential, forms a lasting interest in fine art and increases the aesthetic values of the children's paintings.

\section{Literature}

Marinov, A. (2002). Children's drawings and modern art. Pleven, Pleven: lege Artis./ Marinov, A. (2002). Detski risunki I moderno izkustvo. Pleven, Pleven: lege Artis. ISBN 954-9933-28-8

Moinova, M. (2016). Children's painting as a culture phenomenon. Veliko Tarnovo, VT: Exlibris Studio./ Moinova, M. (2016). Detskata risunka kato fenomen na kulturata. Veliko Tarnovo, VT: Exlibris Studio. ISBN 978-619-90391-4-4 Vigotski, L. (1982). Imagination and Creativity in Childhood. Sofia, Sofia: Nauka I izkustvo./ Vigotski, L. (1982). Vuobrazhenie I tvorchestwo na deteto. Sofia, Sofia: Nauka I izkustvo.

Zlateva, A. (2005). Drawing exercises. Stara Zagora, StZ: Daga +./ Zlateva, A. (2005). Risuvatelni uprazhnenia. Stara Zagora, StZ: Daga +. ISBN 954-91440-6-2 